\title{
MEMÓRIA EM DESDOBRAMENTOS: EFEITOS DE SENTIDO EM REDE
}

\author{
MEMORY IN DEVELOPMENTS: EFFECTS OF MEANING IN THE NETWORK
}

Paula Daniele Pavan ${ }^{1}$

\begin{abstract}
RESUMO: Amparado na Análise do Discurso (AD) pecheutiana, este texto explora a noção de memória em diferentes desdobramentos para analisar como através das redes da internet se tornam possíveis outros efeitos de sentido, fazendo circular novas/outras formas de pensar, de ser, de sentir e de viver. Para tanto, o texto divide-se em momentos teórico-analíticos e o corpus de análise é formado por recortes do site Índios Online. O primeiro momento traz discussões sobre a memória do/no digital para compreender como, por um lado, o site pode conformar uma memória quantitativa e, por outro, pode produzir uma memória (discursiva) digital do/sobre os povos indígenas. Já o segundo momento traz a noção de memória cultural a partir de um jogo entre tradição e invenção, que ocorre no movimento entre saberes do discurso indígena e saberes do discurso da informatização.
\end{abstract}

Palavras-chave: Memória; efeitos de sentido; redes da internet.

ABSTRACT: Based on the Pecheutian Discourse Analysis (AD), this text explores the notion of memory in different developments to analyze how through the internet networks become possible other effects of meaning the circulation of new/other ways of thinking, being, feeling and living. To this end, the text is divided into theoretical-analytical moments and the corpus of analysis consists of clippings from the Indios Online website. The first moment brings discussions about memory of / in the digital to understand how, on the one hand, the website can form a quantitative memory and, on the other hand, it can produce a digital (discursive) memory of / about these people. The third moment brings the notion of cultural memory from a play between tradition and invention, which occurs in the movement between knowledge of indigenous discourse and knowledge of the computerization discourse.

Keywords: Memory; effects of meaning; internet networks.

\section{Considerações iniciais}

No âmbito da Análise do Discurso (AD) pecheutiana, diversas são as pesquisas que tomam as páginas da web como materialidades significantes de análise, essas abordagens permitem compreender que criar um site e nele escrever textos, publicar imagens, postar vídeos etc. constitui-se enquanto ato simbólico articulado à possibilidade de transformação das condições de produção e de existência.

\footnotetext{
${ }^{1}$ Doutora em Letras - Área de Estudos da Linguagem, Especialidade Teorias do Texto e do Discurso pela Universidade Federal do Rio Grande do Sul - UFRGS. Professora Adjunta da Universidade Federal do Pampa UNIPAMPA, Campus São Borja.
} 
Nesse sentido, a motivação da produção de textos (verbais, imagéticos, visuais) em rede transcende à produção de informação e de conteúdo, pois se inscreve na história e busca reescrevê-la. Ou seja, os espaços da internet aparecem significados como um meio para os grupos e os movimentos sociais conquistarem a possibilidade de dizer, de se incluir e de tomar de certa forma poder. A rede mundial de computadores apresenta-se, portanto, como uma oportunidade para a transformação histórica, cultural, econômica e política.

Sob essa ótica, as redes da internet ultrapassam seu funcionamento técnico, tomado apenas como uma ferramenta, e adquirem um caráter político, sendo apropriadas pelos sujeitos em seus movimentos sociais para travar diferentes lutas e, como apresento neste texto ${ }^{2}$, uma luta pela memória e pela produção de efeitos de sentido, fazendo circular novas/outras formas de pensar, de ser, de sentir e de viver. Uma luta, portanto, pela produção de efeitos de memória diferentes dos já produzidos e pela produção de sentidos que correm o risco de ser esquecidos, apagados e/ou omitidos.

É, então, disto que este texto trata, desses outros efeitos de sentido possíveis, que estão comumente invisibilizados, mas que, através das redes da internet, têm a possibilidade de emergir. Para tanto, a memória em diferentes desdobramentos - metálica, discursiva, discursiva digital e cultural - é mobilizada. Isso com o objetivo de compreender o modo como no site Índios Online ${ }^{3}$ se torna possivel pensar tanto na (con)formação de uma memória (discursiva) no/do digital, quanto no site como um espaço de/para a memória cultural.

\section{A Memória em desdobramentos}

O significante memória pode ser determinado por diferentes adjetivos, indicando a existência de modos díspares de pensá-la. Então, neste percurso sobre a noção, detenho-me inicialmente sobre o seu funcionamento no digital e, após, sobre a sua articulação com a cultura. De forma concomitante, trago recortes do site Índios Online a fim de fazer um batimento entre teoria e análise.

\subsection{Memória no/do digital: da memória metálica à discursiva digital}

Orlandi (1996, p. 15-16) é quem cunha a noção de memória metálica e a define como aquela que lineariza "o interdiscurso", reduzindo o saber discursivo a um pacote de informações”. Assim, conforme a autora, há multiplicação dos meios, mas homogeneização dos efeitos, pois a memória metálica "não falha e [...] se apresenta como ilimitada em sua extensão, só produz o mesmo, em sua variação, em suas combinatórias” (p. 16). Por essa perspectiva, ela diz respeito a uma memória achatada, horizontal, que não produz retornos e/ou desregulação. Isso ocorre na medida em que uma "formulação se transforma em várias outras sem que se

2 Este texto traz reflexões presentes em minha Tese de Doutorado junto a novos olhares que estão sendo trabalhados no Projeto de Pesquisa que coordeno atualmente.

3 Criado em 2004 com o apoio da ONG THYDÊWÁ e reconhecido em 2005 como Ponto de Cultura pelo Ministério da Cultura, o Índios Online define-se como um canal de diálogo, encontro e troca entre culturas de diferentes povos indígenas. Disponível em: 〈https://www.indiosonline.net/>.

4 O interdiscurso refere-se a todos os dizeres já-ditos e a se dizer, assim é marcado pela completude (cfe. PÊCHEUX [1975] 2009). 
toque no domínio da constituição, onde um sentido poderia vir a ser outro, na sua historicidade" (ORLANDI, 2008, p. 182).

Dias (2013, p. 60), ao retomar os pressupostos de Orlandi, afirma que a memória metálica "se constitui através das possibilidades de armazenamento de dados, cada vez maiores, cujo efeito é o da completude". E a internet, nos dias de hoje, é responsável pela criação desse imaginário de completude da memória, tudo e todos estariam na internet. Ainda conforme Dias (p. 69), a memória que vai se formando através dos mecanismos da internet é uma memória do armazenamento, o que a difere da memória discursiva, que é lacunar, incompleta, aberta ao acontecimento e ao esquecimento ${ }^{5}$.

Vale registrar, diante disso, que a memória discursiva é entendida em sua articulação com a história e com as práticas sociais, conforme defende Pêcheux (2007, p. 50): "nos sentidos entrecruzados da memória mítica, da memória social inscrita em práticas, e da memória construída do historiador". A memória é responsável, por essa ótica, pelo restabelecimento, no ato de leitura de toda e qualquer materialidade significante, dos "'implícitos' (quer dizer, mais tecnicamente, os pré-construídos, elementos citados e relatados, discursos-transversos, etc.) de que sua leitura necessita: a condição do legivel em relação ao próprio legível” (p. 52).

Então, através do funcionamento da memória podem emergir no fio do discurso fragmentos discursivos de alhures. Digo "podem" porque o funcionamento da memória discursiva envolve o funcionamento de outras noções do aparato teórico da $\mathrm{AD}$, como a noção de formação discursiva (FD) e de posição-sujeito ${ }^{6}$. Isso na medida em que os sentidos que a memória resgata do interdiscurso, o todo já-dito (PÊCHEUX, 2009), dependem de qual posição-sujeito e de qual FD o sujeito está identificado e enuncia. Conforme afirma Indursky (2011, p. 87), a memória "diz respeito não a todos os sentidos, como é o caso do interdiscurso, mas aos sentidos autorizados pela Forma-Sujeito no âmbito de uma formação discursiva”. Os efeitos de memória (COURTINE, 2009) serão, portanto, diferentes a depender do posicionamento ideológico daquele que enuncia, dos sentidos que lhe são possiveis a partir do domínio de saber em que os seus dizeres se inscrevem.

A memória discursiva não é, portanto, um reservatório com sentidos homogêneos que se mantêm os mesmos ao longo da história, mas deve ser tomada como "um espaço móvel de divisões, de disjunções, de deslocamentos e de retomadas, de conflitos de regularização... Um espaço de desdobramentos, réplicas, polêmicas e contra-discursos” (PÊCHEUX, 2007, p. 56). Por isso, "é feita de esquecimentos, de silêncios. De sentidos não ditos, de sentidos a não dizer, de silêncios e de silenciamentos" (ORLANDI, 2007, p. 59).

Feita essa diferenciação entre o funcionamento da memória metálica e da memória discursiva, recorro a Dias $(2015$, p. 4) quando acrescenta o que nomeia como memória digital:

\footnotetext{
5 Enquanto o acontecimento está articulado à desestabilização de sentidos anteriores e à irrupção de novos sentidos (cfe. PÊCHEUX [1983] 2008; INDURSKY, 2003); o esquecimento pode se referir tanto àquilo que é esquecido por conta da identificação ideológica, quanto ao esquecimento que abre lacunas, deixando brechas para que os sentidos se transformem (cfe. COURTINE, 1999).

6 A FD determina "o que pode e deve ser dito (articulado sob a forma de uma arenga, um sermão, de um panfleto, de uma exposição, de um programa, etc)” (PÊCHEUX, [1975] 2009, p. 147). Já a posição-sujeito configura-se como uma "relação determinada que se estabelece em uma formulação entre um sujeito enunciador e o sujeito do saber de uma dada FD” (COURTINE, [1981] 2009, p. 88).
} 
[...] la mémoire métallique se constitue par l'excès, par la quantité. Elle n'oublie pas, ni même n'institutionnalise ni ne normalise pour ne pas oublier, mais additionne, accumule, raison pour laquelle nous la comprenons comme une mémoire numérique. [...] pour la mémoire métallique, l'espace de circulation des sens est un espace virtuel où tout se tient, où rien ne manque, et où l'archive devient éternelle. (grifos meus) ${ }^{7}$

Embora nomeada de forma distinta, ainda é possível observar a similitude entre a memória metálica e a memória digital. Para a autora, elas não são distintas, pautam-se na quantidade e no excesso, não na falha e no esquecimento característicos da memória discursiva. Por outro lado, Dias $(2015$, p. 2) também afirma que "toute variation de la forme matérielle se reflète nécessairement sur les sens [...]. Ces transformations dans la forme matérielle bouleversent également la notion de mémoire, une fois qu'elles modifient l'historicité du sens." . Então, embora a autora não distinga a memória metálica da memória digital, aqui estão alguns indícios de que a memória metálica quando pensada no âmbito do ciberespaço, como atualmente se apresenta, pode produzir efeitos de sentido diversos daqueles apenas do acúmulo e do excesso.

É ao fazer uma distinção entre memória como espaço (de estocagem) e memória como tempo (esquecimento), ainda nesse texto, que Dias $(2015$, p. 8) nos encaminha a observar que no ciberespaço não há apenas lugar para o acúmulo produzido pela estocagem, mas também há lugar para o esquecimento e para a deriva dos sentidos. Por esse viés, a materialidade (do) digital pode produzir uma "fugue du sens qui met en marche la mémoire discursive de l'evénement, différentes d'une mémoire de l'espace. Cette mémoire que se détache de la mémoire métalique de la chose répliquée [... $]^{9 ”}$ (p. 10).

É para essa possibilidade de alteração dos sentidos que aponta Paveau (2013) ao propor uma "mémoire numérique au sens technodiscursif, et non au sens informatique" ${ }^{10}$ (PAVEAU, 2013, p. 1). Esse sentido tecnodiscursivo é uma forma de conjugação entre discurso e técnica, levando a compreender que "les énoncés produits em ligne sont constitués d'une matière hybride, et non plus seulement langagière" ${ }^{11}$ (p. 3). Assim, apresenta-se, na visão da autora, a possibilidade de formular a noção de mémoire discursive numérique - memória discursiva digital.

Os conceitos de redocumentação e rememoração são, de acordo com Paveau, produtivos para fundar esse novo conceito. Para a autora (citando Yahiaoui et al. 2007), a redocumentação é uma reprise, no sentido de um novo documento gerado pela utilização da máquina, como, por exemplo, os tweets no Twitter, o status no Facebook, fotos e vídeos em rede etc. Assim, a redocumentação torna-se "une forme de rémémoration, c'est-à-dire d'elaboration d'une

\footnotetext{
7 [...] a memória metálica se constitui pelo excesso, pela quantidade. Ela não esquece, não se institucionaliza e nem se normatiza para não esquecer, mas adiciona, acumula, razão pela qual a compreendemos como uma memória digital. [...] Através da memória metálica, o espaço de circulação do sentido é um espaço virtual onde tudo cabe, onde nada falta, e onde o arquivo se torna eterno. (Tradução minha)

8 "Toda variação da forma material se reflete necessariamente sobre os sentidos [...]. Essas transformações na forma material perturbam também a noção de memória, uma vez que modificam a historicidade do sentido”. (Tradução minha)

9"Fuga do sentido que aciona a memória discursiva do acontecimento, diferente de uma memória do espaço. Essa memória que se distancia da memória metálica da repetição". (Tradução minha)

10 "memória digital no sentido tecnodiscursivo, não no sentido da informática" (Tradução minha)

11 "os enunciados produzidos on-line constituem-se de uma matéria híbrida, e não apenas linguageira".(Tradução minha)
} 
mémoire à partir d'un éparpillement de traces numériques" ${ }^{12}(2013$, p. 3). Já no que se refere especificamente à rememoração, a autora entende que ela é uma forma de recriação de memória, pois "Ce que permet le numérique, ce n'est pas simplement d'accumuler des traces ou même de les remanier. C'est surtort de garder la trace de ce que nous faisons de ces traces [...]"13 (HABERT, 2012, p. 17 apud PAVEAU, 2013, p. 4). Esta é, de acordo com sua perspectiva, a possibilidade de reflexividade da memória digital, a qual indica a capacidade de historicização e verticalização da memória.

Dito isso, tomemos como objeto de observação a página inicial do Índios Online.

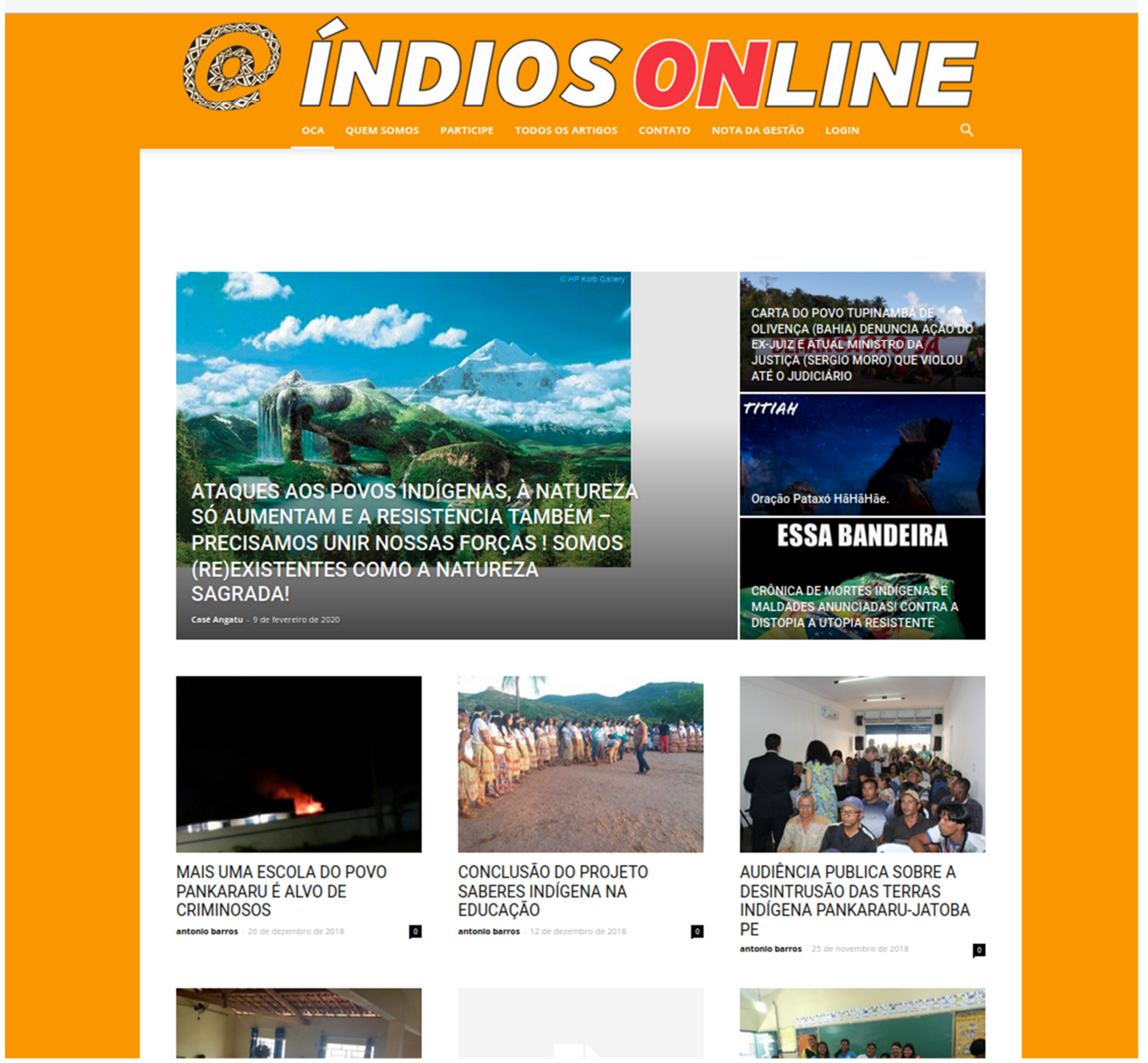

Disponivel em: <https://www.indiosonline.net/>.

Se pensarmos os textos (verbais, imagéticos, sonoros e visuais) que ali se constituem e passam a circular pela ótica da memória metálica e/ou da memória digital, tal como concebidas por Orlandi $(1996 ; 2008)$ e Dias $(2013 ; 2015)$, somos levados a observar que esse espaço digital conforma uma memória de informações e de dados sobre os povos indígenas. Uma memória que se pauta no acúmulo, na quantidade e no excesso - uma memória quantitativa, que pode

12 "[...] uma forma de rememoração, ou seja, de elaboração de uma memória a partir de uma dispersão de dados digitais”. (Tradução minha)

13 "O que o digital permite não é apenas acumular dados ou mesmo modificá-los. É sobretudo guardar dados do que nós fazemos com os dados”. (Tradução minha) 
ser replicada inúmeras vezes através da internet. Ou seja, por essa perspectiva, o site funciona a partir de uma memória com função de depósito de textos.

É esse efeito de sentido que também ocorre ao clicarmos na aba "Todos os artigos".

Vejamos:
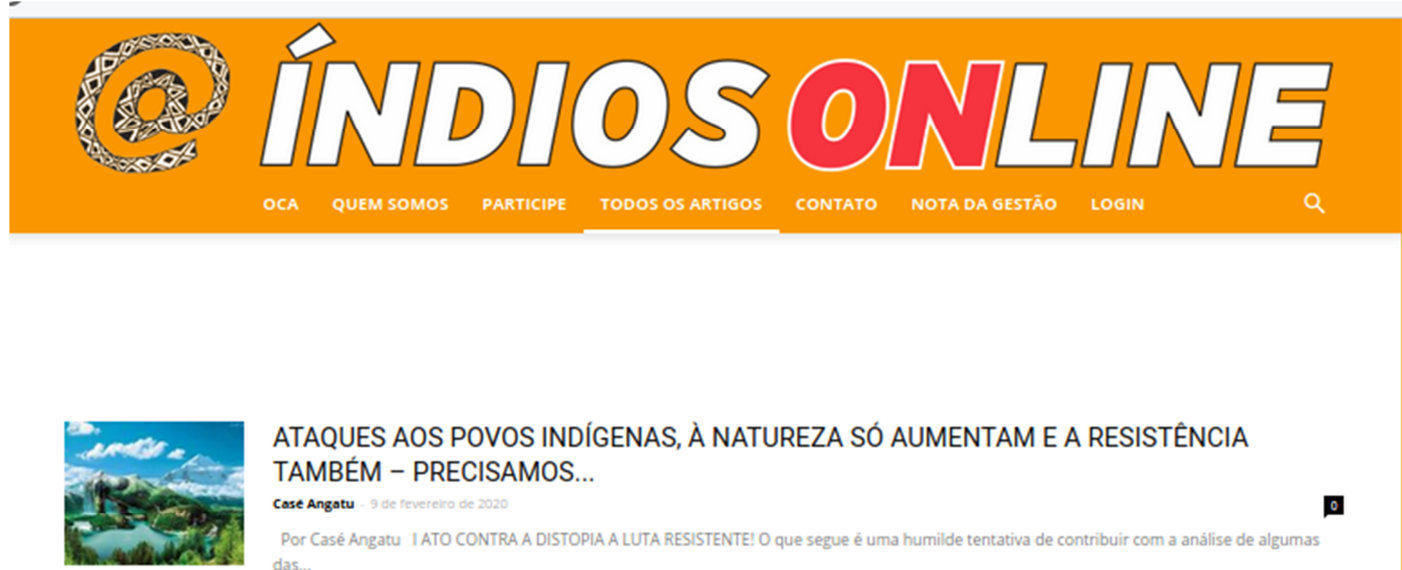

ATAQUES AOS POVOS INDÍGENAS, À NATUREZA SÓ AUMENTAM E A RESISTÊNCIA TAMBÉM - PRECISAMOS...

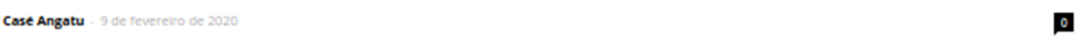

Por Casé Angatu I ATO CONTRA A DISTOPIA A LUTA RESISTENTE! O que segue é uma humilde tentativa de contribuir com a análise de algumas

das....

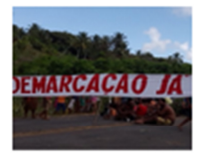

CARTA DO POVO TUPINAMBÁ DE OLIVENÇA (BAHIA) DENUNCIA AÇĀO DO EX-JUIZ E ATUAL MINISTRO...

Case Angatu 30 oe panciro de 2020

VIOLOU ATE O OUDICLRRIO MAIS.

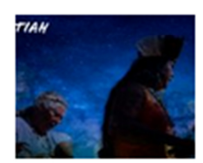

Oração Pataxó HãHãHãe.

Quando meu povo pisa no chảo, a terra treme. Quando balaçămos o nosso maracá, trazemos a força que move o mundo. Quando gritamos

cantamos, fazemos...

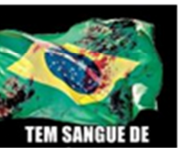

CRÔNICA DE MORTES INDÍGENAS E MALDADES ANUNCIADAS! CONTRA A DISTOPIA A UTOPIA RESISTENTE

case Angatu

CRESCIMENTO DE ASSASSINADOS DE INDIGENAS, DA POPULAÇAO POBRE NAS CIDADES, O PACOTE DE MALDADES DE MORO (CRIMINIALIZACAO

ÉTNICA E SOCIAL), AS ESQUERDAS" E OS.

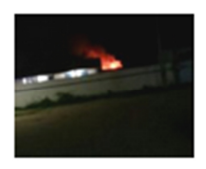

MAIS UMA ESCOLA DO POVO PANKARARU É ALVO DE CRIMINOSOS

Na madrugada do dia 26 de Dezembro de 2018, mais uma Escola indigena do Povo Pankararu foi incendiada em ato criminoso, e desta vez

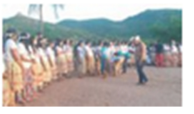

Na ultima segunda feira, dia 11 de Dezembro no terreiro do poente do povo pankararu aconteceu a...

Disponível em: <https://www.indiosonline.net/arquivos/>.

Ao acessarmos essa aba, temos a produção do efeito de armazenamento, de completude, de estocagem, como se não houvesse nada sobrando e nem faltando, conforme a visão de Dias (2015) ao afirmar que o espaço da memória metálica é aquele onde cabe tudo e há eternidade do arquivo de textos. No entanto, conforme vimos, Dias (2015) também deixa entrever que o digital afeta de certa forma a história dos sentidos, isto é, através do digital outros/novos 
sentidos podem se constituir e passar a circular, e aí tocamos no domínio da memória discursiva.

É isso que podemos entender se olharmos esses mesmos espaços pela ótica da memória discursiva digital, defendida por Paveau (2013). Isso ao passo que há através dos textos que ali se materializam a possibilidade de uma nova organização das redes de memória sobre os povos indígenas. Ou seja, escrever e publicar esses textos na rede digital faz com que se toque numa rede discursiva que é anterior e posterior, pois, como já alertava Pêcheux (2008, p. 56), o discurso não é um "aerólito miraculoso, independente das redes de memória e dos trajetos sociais nos quais ele irrompe", pois "só por sua existência, todo discurso marca a possibilidade de uma desestruturação-reestruturação dessas redes e trajetos”. Por essa ótica, a publicação, organização e reunião de textos na aba "Todos os artigos" forma um arquivo digital sobre a causa indígena. Um novo arquivo, singular em sua circulação e discursivização, pois esses documentos não significam mais da mesma forma - há a junção do discurso indígena e do discurso da informatização.

Sob essa perspectiva, entendemos que através das materialidades (textos verbais, imagéticos e visuais) do site tem-se a possibilidade de mexer na constituição dos sentidos e de se elaborar uma memória (discursiva) digital do/sobre os indígenas, uma memória constituída através da redocumentação e da rememoração, isto é, da possibilidade de criação de novos/outros documentos possíveis pelos dispositivos e redes digitais, de novas/outras redes de memória e também de novas/outras leituras, visto que os objetos simbólicos que ali se encontram se oferecem à leitura e à interpretação, colocando em jogo e em circulação efeitos de sentido antes pouco visíveis ou até mesmo invisíveis. $O$ que torna possível, conforme defende Ferreira (2013) ao analisar a autoria indígena em blogs, um processo de resistência dos povos indígenas em relação aos discursos que circulam principalmente na mídia tradicional.

Sentidos esses que estão em relação com a cultura desses povos e com aquilo que eles lutam para ser lembrado.

\subsection{Memória cultural}

Assmann e Assmann (2013; 2016), teóricos alemães e estudiosos da cultura, são quem propõem o conceito de memória cultural, numa retomada da noção de memória coletiva abordada pelo sociólogo francês Maurice Halbwachs.

Jan Assmann (2013), em conferência realizada no Instituto de Estudos Avançados da Universidade de São Paulo, afirma que as coisas não têm uma memória própria, mas elas podem ser o gatilho para nos lembrar, isso na medida em que carregam as memórias nelas investidas. Para ele, são os ritos, as imagens, as celebrações, as paisagens, os monumentos, as narrativas, as músicas, as máscaras, os símbolos, as danças etc. que constituem a memória cultural. Nessa perspectiva, entende que a memória cultural se baseia em pontos fixos do passado, que retorna através de símbolos, como os mitos, os escritos e as celebrações, sendo que para dela fazer parte essas práticas simbólicas devem se pautar na repetição.

Nessa mesma esteira, Aleida Assmann (2013) entende que a memória cultural é um sistema de valores, de artefatos, de instituições, de práticas, que retêm o passado para o presente e para o futuro. Além disso, a autora entende que a memória cultural possui duas formas de organização, que junto atuam: a repetição (oral) e a duração (escrita). A repetição ocorre, segundo ela, por meio de teatro, de histórias e de narrativas, como uma herança cultural 
intangível; já a duração tem a ver com o armazenamento através da mídia, dos textos, das imagens, dos documentos e de locais de memória, como bibliotecas e museus.

Seguindo essa perspectiva, em outro texto, Assman (2016, p. 118) defende que a memória cultural se produz pela possibilidade de ser "exteriorizada, objetivada e armazenada em formas simbólicas que, diferentemente dos sons de palavras ou da visão dos gestos, são estáveis e transcendentes à situação: elas podem ser transferidas de uma situação a outra e transmitidas de uma geração a outra.”. No entanto, sob a ótica do autor, não se pode confundir a memória cultural com a memória comunicativa, pois enquanto a memória cultural é institucionalizada e possui guardiões daquilo que deve perdurar no tempo, a memória comunicativa se aproxima das interações e comunicações cotidianas, sendo mais difusa (Ibid., p. 119).

Isso posto, podemos observar que a memória cultural, conforme as definições dos autores, tem a ver com a rememoração, armazenamento e transmissão de sentidos já produzidos no passado. O que se torna possível através tanto da repetição produzida através de práticas simbólicas (ritos, celebrações etc.), quanto por meio de materialidades (imagens, monumentos etc.) que resguardam o passado. Esse é, pois, o ponto que retenho da noção de memória cultural proposta pelos Assmann, pois é pela perspectiva do retorno de sentidos que a memória interessa discursivamente.

Levando esses pressupostos em conta e buscando localizar a memória cultural no aparato teórico-metodológico da AD, recorro a Leandro Ferreira (2011, p. 61), baseada em Chauí (2006), quando afirma que é possível "pensar a cultura funcionando como um lugar da produção social da memória e do esquecimento". Conforme a autora, como lugar de memória, a cultura conserva e reproduz "artefatos simbólicos e materiais de geração em geração". Já como lugar do esquecimento, a cultura comporta exclusões e apagamentos, "que os sujeitos produzem, inconscientemente, nos modos de ser, representar e estar em sociedade."

Tomando como base a afirmação da autora e articulando ao que os Assmann (2013) afirmam, é possível pensar a cultura como portadora de memória, uma memória cultural lugar de conservação e de reprodução que encaminha para a tradição. Dito de outro modo: a memória cultural sendo pautada pela repetição, regularização e perpetuação de determinados sentidos - através de rituais, modos de ser, de estar, de enunciar etc. Mas não apenas. Se consideramos o acontecimento e o esquecimento, podemos pensar que na memória cultural há também um movimento que indica a invenção. Ou seja, além do esquecimento que se refere às exclusões, do qual fala Leandro Ferreira (2011), há também o esquecimento que abre lacunas, deixa brechas para que os sentidos - provenientes desses rituais e práticas - não apenas se conservem, mas também se modifiquem, se desloquem e deslizem.

Sobre a relação entre tradição e cultura, De Nardi (2007, p. 53) afirma que é necessário diferenciar uma da outra, pois "Reduzir a cultura à tradição é negar seu caráter dinâmico, considerando parte da cultura apenas aquilo que se sedimentou", isso ao passo que a cultura possui "uma dimensão político-histórico-social que lhe garante a possibilidade de ser dinâmica e crítica, de propor rupturas, de produzir outros dizeres". Assim, é possível compreender a dinamicidade da cultura, nos encaminhando a pensar a memória cultural a partir de um jogo pendular entre a sedimentação (tradição) e a movimentação (invenção). Além disso, do ponto de vista da tradição, a memória cultural funciona como um lugar de preservação, conservação e fortalecimento de determinados rituais, normas, modos etc. Já sob a ótica da invenção, a memória cultural está aberta ao devir e às possíveis rupturas naquilo que já estava sedimentado. 
Ao relacionar esses pressupostos teóricos ao que se materializa no Índios Online podemos observar que ali ocorre um processo de ressignificação da rede mundial de computadores no seio do movimento social, colocando em jogo uma relação entre tradição e invenção. Vejamos o recorte a seguir:

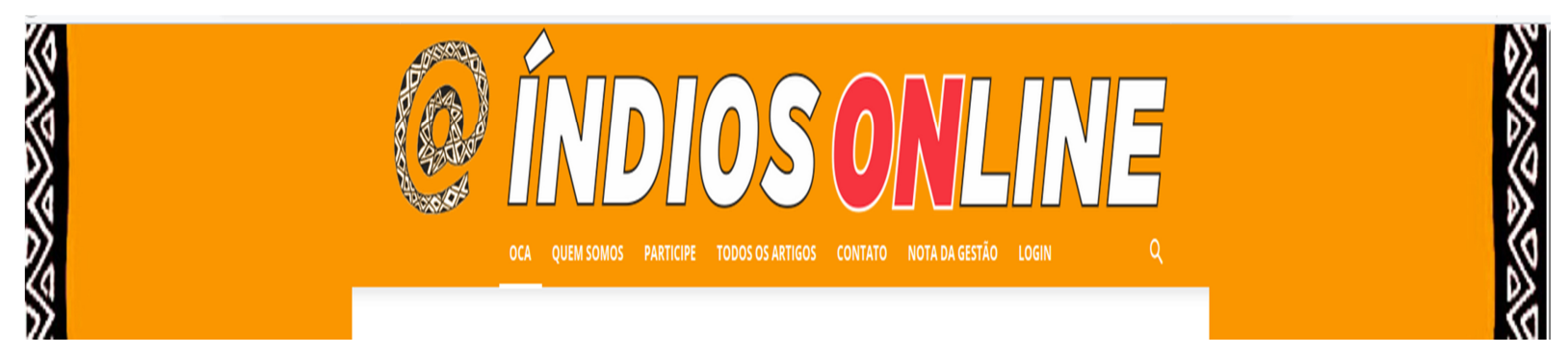

Disponível em: <https://www.indiosonline.net/>.

Fazendo um batimento teórico-analítico, podemos compreender que a formulação verbal “oca”, o símbolo arroba @ e a formulação imagética constituída pela iconografia indígena colocam em funcionamento a memória cultural do movimento social conjugada com a memória discursiva digital. Isso ao passo que mobilizar um significante que designa uma típica habitação indígena dando-lhe a função de comando da página principal do site, ao utilizar a iconografia indígena, que possui um alto valor simbólico para os povos indígenas por informar sobre sua cultura, cosmovisão, mitologias e organização social (CAVALCANTE et al., 2013), tanto na lateral da página quanto para caracterizar um ícone da informatização (@), se torna possível observar um movimento de sentidos do que é próprio do discurso indígena e do que é característico discurso da informatização. Esse movimento coloca em cena o jogo pendular entre tradição e invenção, que constituem o que estamos entendendo como memória cultural, lugar de conservação [oca, iconografia indígena] e também de mudança [oca página inicial do portal, iconografia indígena no digital].

Vale registrar, diante disso, que a apropriação que o grupo social faz da informática ocorre no sentido de sobrepor o que vem da sua memória cultural ao que vem da informatização. Isso aponta um movimento inverso ao que é observado por Mittmann (2010), pois, em sua análise dos sites de movimentos sociais, a autora mostra que há uma certa submissão desses movimentos à ordem da informatização. Mais precisamente, através de expressões próprias das TICs, de menus nas páginas, de arquivos e sub arquivos etc., ocorre uma adaptação da mobilização política ao ciberespaço.

Além desse funcionamento, retomando a perspectiva dos Assmann (2013; 2016), é possível observar que o movimento social se apropria do site para guardar o passado para o futuro, para armazenar aquilo que, a partir da sua tomada de posição, realmente importa, que deve ser transmitido e lembrado.

O site pode se apresentar, assim, como um lugar de memória (cultural), conforme a definição de Pierre Nora (1993), pois reúne aquilo que precisa rememorado pelo movimento social. Isso na medida em que "Os lugares de memória nascem e vivem do sentimento que não há memória espontânea, que é preciso criar arquivos" (p. 13), pois "Se habitássemos ainda nossa memória, não teríamos de lhe consagrar memórias. Não haveria lugares porque não haveria memória transportada pela história.” (p. 8). Então, por essa ótica, os lugares de 
memória surgem num ímpeto de resguardar através de documentos e monumentos sentidos para o presente e o futuro. Conforme destaca Indursky (2011, p. 73), em sua leitura sobre os lugares de memória, ao afirmar que esses lugares se constituem como "traços vivos constituídos no entrelaçamento do histórico, cultural e simbólico.”

Vejamos, então, uma materialidade significante presente no Índios Online que nos faz enxergá-lo como um lugar de memória cultural para os povos indígenas:

\section{Oração Pataxó HãHãHãe.}

Por fabriciotitiah - 8 de janeiro de $2020 \quad$ O 257

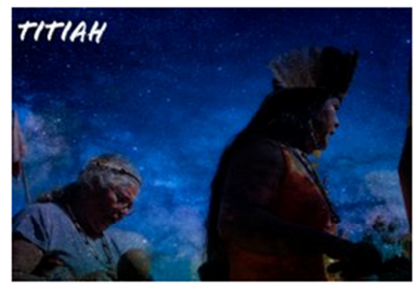

Quando meu povo pisa no chão, a terra treme.

Quando balaçamos o nosso maracá, trazemos a força que move o mundo.

Quando gritamos e cantamos, fazemos ecoar a voz da natureza.

Quando acendemos o cachimbo sagrado, expulsamos toda negatividade com a fumaça, e nos conectamos com nós mesmos.

E a nossa fogueira no meio, o grande fogo, representando o equilíbrio, pois o fogo nos alimenta e nos destrói se não soubermos usá-lo.

Inícia o nosso ritual sagrado, o nosso Awê.

Os nossos Encantados quando descem para celebrar conosco, fazem o mundo rodopiar, pisando com força e peneirando no ar igual gavião. Nós, Pataxó HãHãHãe, somos a união de 5 grandes forças. Somos Baenã, Kiriri Sapuyá, Tupinambá, Kamakã e Pataxó. Quando essas forças conectadas dançam o Awê, faz correr um furacão na terra. Na força das pisadas dos povos indígenas é que mantém o mundo em equilíbrio. É nas nossas pisadas que trazemos o código pra conectarmos com a nossa mãe Terra. Nossa força vem do grande ventre materno: $\mathrm{A}$ Natureza.

Viva a nossa acestralidade!

Viva as forças da natureza!

Awêry!

Texto: Fabrício Titiah

FotolArte: Fabricio Titiah

Disponível em: <https://www.indiosonline.net/oracao-pataxo-hahahae/>.

Ao nos depararmos com essa publicação, percebemos que não são quaisquer textos que o site abriga para a posteridade, são textos que materializam suas crenças, seus modos de viver e suas lutas, narrativas que devem ser não apenas resguardadas para as gerações futuras, mas também conhecidas, lidas e interpretadas por todos aqueles que acessam o site.

É o que ocorre com o texto do recorte apresentado, um texto sagrado que exalta elementos considerados dignos de lembrança para os povos indígenas, quais sejam: a terra e a natureza. Assim, a profissão de fé encontra nas redes da internet lugar para ser lembrada e registrada, colocando em jogo tradição (texto sagrado) e invenção (redes da internet), que constituem a memória cultural sob a ótica discursiva. 


\section{Considerações Finais}

Os desdobramentos da memória apresentados ao longo deste texto permitem observar que as redes da internet não são apenas redes técnico-ferramentais, que transportam dados e informações, mas também são redes de sentidos, redes que têm o potencial de colocar em jogo efeitos de sentido diversos daqueles produzidos pela ideologia dominante. Assim, a apropriação da tecnologia pelos movimentos sociais aponta a necessidade de (re)pensar o funcionamento da memória.

Esta abordagem permitiu-nos observar, portanto, que a relação entre memória e novas tecnologias faz parte de um percurso em evolução no seio dos estudos da AD.

Isso porque se inicialmente Orlandi (1996) cunha a noção de memória metálica para observar o modo como funciona pelo acúmulo e pela produção do mesmo, e Dias (2013; 2015), nessa mesma esteira, trata o metálico e o digital como formas semelhantes de memória que atuam na armazenagem de dados, produzindo a completude; Paveau (2013), ao tratar sobre o discurso (no) digital, promove um deslocamento dessas perspectivas ao incorporar o discursivo no funcionamento das ferramentas e dos mecanismos do ciberespaço, mostrando-nos como as conexões em rede, mais do que apenas reunir, estocar, armazenar, transportar etc., tornam possível a produção de sentidos-outros mediante movimentos de ressignificação. E é esse movimento de ressignificação que, a nosso ver, se materializa no site Índios Online, o que não ocorre na ordem do metálico, mas na ordem da memória discursiva digital.

Esse funcionamento possibilitou discutir também a noção de memória cultural e repensá-la sob a ótica discursiva, pois observamos que ocorre a ressignificação da rede mundial de computadores no âmbito do movimento social, colocando em jogo uma relação entre saberes culturais próprios do movimento indígena, indicando a presença da tradição, e saberes tecnológicos, assinalando a invenção. Além disso, propomos a perspectiva de que o site pode funcionar como um lugar de memória cultural para os povos indígenas, pois ali podem perpetuar aquilo que corre o risco de ser esquecido.

Eis, portanto, um percurso sobre a memória que possibilita mostrar a necessidade da apropriação da tecnologia pelos movimentos sociais.

\section{Referências}

ASSMANN, J.; ASSMANN, A. Conferência Memória comunicativa e cultural. In: Instituto de Estudos Avançados da Universidade de São Paulo, 2013. Disponível em: <http://www.iea.usp.br/midiateca/video/videos-2013/memoria-comunicativa-e-cultural>. Acesso em 17 jun. 2015.

ASSMANN, J. Memória comunicativa e memória cultural. História Oral, v. 19, n. 1, pp. 115 127, jan./jun. 2016. Disponível em:

$<$ http://revista.historiaoral.org.br/index.php?journal=rho\& page $=$ article\&op $=$ view\& ath\%5B\% $5 \mathrm{D}=642 \&$ path $\% 5 \mathrm{~B} \% 5 \mathrm{D}=\mathrm{pdf}>$. Acesso em 20 abr. 2020

CAVAlCANTE, A. L. B. L.; ROSSATO, J.; PEREIRA, F. A. F.; PERASI, R. L. S. A Iconografia em comunidades indígenas. Projética, v. 4, pp. 9-28, 2013. Disponível em: 
<http://www.uel.br/revistas/uel/index.php/projetica/article/viewFile/16043/14237>. Acesso em 22 ago. 2016.

COURTINE, J. J. Análise do discurso político: o discurso comunista endereçado aos cristãos. São Carlos, SP: EDUFSCar, 2009.

COURTINE, J. J. O chapéu de Clémentis. Observações sobre a memória e o esquecimento na enunciação do discurso político. In: INDURSKY, F.; LEANDRO FERREIRA, M. C. (org.). Os múltiplos territórios da Análise do Discurso. Porto Alegre: Sagra Luzzatto, 1999.

DE NARDI, F. S. Um olhar discursivo sobre língua cultura e identidade: reflexões sobre o livro didático para o ensino de espanhol como língua estrangeira. Tese de Doutorado. Universidade Federal do Rio Grande do Sul, 2007.

DIAS, C. A poética do cotidiano da rede. Signo y seña, n. 24, pp. 57-70, 2013. Disponível em: <http://revistascientificas.filo.uba.ar/index.php/sys/article/view/3208/2844>. Acesso em 20 abr. 2020.

DIAS, C. L'écriture du fragmentaire quotidien entre mémoire discursive et mémoire métallique. Itinéraires [En ligne], 2014-1/2015. Disponível: <http://itineraires.revues.org/2289> DOI: 10.4000/itineraires.2289. Acesso em 20 mai. 2015.

FERREIRA, L. L. Vozes indígenas na rede digital: discurso e autoria em blogs. Tese de Doutorado. Universidade Estadual de Campinas, 2013.

INDURSKY, F. A memória na cena do discurso. In: . et al. Memória e história na/da análise do discurso. Campinas: Mercado de Letras, 2011.

INDURSKY, F. Lula Lá: estrutura e acontecimento. Revista Organon, Porto Alegre, v. 17, n. 35, pp. 101-121, 2003.

LEANDRO FERREIRA, M. C. O lugar do social e da cultura numa perspectiva discursiva. In: INDURSKY, F.; LEANDRO FERREIRA, M. C.; MITTMANN, S. (org.). Memória e história da/na Análise do Discurso. Campinas, SP: Mercado de Letras, 2011.

MITTMANN, S. Movimentos sociais no ciberespaço: o cruzamento de duas ordens discursivas. In: RIBEIRO, A. E. et al. (org.). Linguagem, tecnologia e educação. São Paulo: Petrópolis, 2010.

NORA, P. Entre memória e história: a problemática dos lugares. Projeto História. São Paulo: PUC-SP. n 10, p. 12, 1993.

ORLANDI, E. P. Interpretação: autoria, leitura e efeitos do trabalho simbólico. Petrópolis, Rio de Janeiro: Vozes, 1996.

ORLANDI, E. P. Maio de 1968: os silêncios da memória. In: ACHARD, P. et al. Papel da memória. 2. ed. Campinas, SP: Pontes Editores, 2007.

ORLANDI, E. P. Discurso e texto: formulação e circulação dos sentidos. Campinas, SP: Pontes, 2008.

PAVEAU, M.-A. Discours et mémoire - La mémoire numérique. Réflexivité et technodiscursivité. In: _____. La pensée du discours: La théorie du discours ouverte à de nouvelles épistémologies (site). Publicado em 05/10/2013. Disponível em: <http://penseedudiscours.hypotheses.org/8204>. Acesso em mai. 2015.

PÊCHEUX, M. Semântica e discurso: uma crítica à afirmação do óbvio. 4. ed. Campinas: Editora da Unicamp, 2009. 
PÊCHEUX, M. Papel da memória. In: ACHARD, P. et al. (org.). Papel da memória. 2. ed. Campinas, SP: Pontes Editores, 2007.

PÊCHEUX, M. O discurso: estrutura ou acontecimento. 5. ed. Campinas: Pontes, 2008.

Recebido em: 14/05/2020

Aceito em: 27/06/2020 